\title{
Jogo TransRisco: identificação do comportamento de risco em condutores
}

\author{
Amanda B. Balbinot ${ }^{1}$, Maria Isabel Timm ${ }^{1}$, Milton Antônio Zaro \\ Programa de pós-graduação de Informática na Educação - Universidade Federal do Rio \\ Grande do Sul (UFRGS) -Porto Alegre - RS - Brazil \\ ambalbinot@gmail.com, zaro@ibtec.org.br
}

\begin{abstract}
Resumo. Este artigo apresenta o jogo TransRisco, destinado a auxiliar na área de educação e segurança de trânsito. $O$ interesse principal deste trabalho é a investigação e $o$ desenvolvimento de um instrumento, jogo, que permita identificar e avaliar a ocorrência de comportamentos de risco em condutores. A identificação de forma precoce de fatores preditores de comportamentos de risco no trânsito tem sua relevância por corroborar para a efetividade das intervenções preventivas na área de trânsito.
\end{abstract}

Palavras-chave: Jogo de trânsito, Comportamento, Condutores, Educação para o Trânsito, Segurança no Trânsito.

\section{Game TransRisco: instrument for the identification of risk behaviors of drivers}

Abstract. This article presents the game TransRisco, to assist in education and traffic safety. The main interest of this work is research and development of an instrument, game, identifying and evaluating the occurrence of risk behaviors in drivers. The identification of precocious predictors of risky behavior in traffic is relevant for the effectiveness of preventive interventions in the transit area.

Keywords: game traffic behavior, drivers, Traffic Education, Traffic Safety

\section{Introdução}

Os acidentes de trânsito, em todo o mundo, apresentam o erro humano como responsável em mais de $90 \%$ dos casos. Principais imprudências registradas, no Brasil são o excesso de velocidade, uso de celular ao volante, ultrapassagem de semáforo vermelho e dirigir sem cinto de segurança. Neste cenário a falha humana é considerada a principal causa de acidentes de trânsito. Investir na formação de condutores parece ser uma medida importante, para a redução deste problema. A aprendizagem veicular exige do aprendiz a manifestação das capacidades e aquisições de habilidades motoras, sensoriais, funções cognitivas, além de informações sobre o trânsito, suas implicações técnicas, preventivas, defensivas e punitivas. As funções cognitivas, quando relacionadas à direção veicular incluem "a memória e 
atenção, a avaliação sistemática do ambiente e outras habilidades visuoespaciais, verbais e de processamento de informações, tomada de decisões e resolução de problemas. (PIRITO, 1999. p.27). No entanto, nos deparamos muitas vezes com a falta de uma cultura educacional que relacione as deficiências dos condutores com as necessidades da educação para o trânsito.

Conforme Diógenes (2004), no Brasil, a maioria dos planos, programas e ações voltados para a segurança viária ainda são formulados a partir da experiência e da intuição dos técnicos. Os programas de direção defensiva existentes ${ }^{1}$ em sua grande maioria são teóricos, com conceitos sobre atitudes defensivas. As avaliações nesses cursos são compostas por questões de múltipla escolha sobre conceitos. Para Backlund et al. (2008), no processo de formação de condutores, os instrutores de trânsito utilizam diversos instrumentos, tais como papel, caneta, vídeos, imagens e computadores. Entretanto, muitas vezes, esses instrumentos não abrangem áreas específicas do ato de dirigir, como o tempo de reação e a atenção, as quais poderiam predizer aspectos sobre as ações do sujeito ao conduzir um veículo. Os autores consideram que simuladores de condução, tornam-se ferramentas úteis, proporcionando experiências em simulações de condições reais de trânsito, permitindo ao jogador interagir virtualmente com o trânsito e acompanhar seu desempenho. Evidenciando assim, a aplicabilidade de jogos área de educação e segurança no trânsito.

Desta forma, apresenta-se, neste artigo, o desenvolvimento do jogo TransRisco o qual objetiva verificar os procedimentos realizados pelo jogador frente a situações específicas de trânsito, identificando comportamentos de risco em condutores. Realizou-se uma avaliação dos principais comportamentos relacionados ao risco de acidentes, por meio de pesquisas realizadas em diversos países, com a aplicação do Questionário do comportamento de motorista (QCM), e conjuntamente com o levantamento das infrações mais cometidas no trânsito de Porto Alegre. Objetivando-se assim, auxiliar na avaliação de condutores, propiciar um feedback para sua autoavaliação e propiciar subsídios para programas voltados a área de trânsito.

\section{Condutores e o comportamento no trânsito}

A relação estabelecida entre o trânsito e o condutor requer deste último responsabilidade, conhecimento e atitudes. Os novos condutores, conforme Konstantopoulos e Crundall (2008) estariam sob maior risco de acidentes, e uma das hipóteses considerada é a de que eles ainda não desenvolveram estratégias para oportunizar a procura visual como o faz motoristas mais experientes. Uma possível explicação seria de que as demandas cognitivas presentes no ato de dirigir são elevadas, e os jovens não seriam capazes de priorizar um adequado domínio cognitivo visual devido à sobrecarga.

${ }^{1}$ Exemplos disponíveis em sites dos DETRANs.

V. $8 \mathrm{~N}^{\mathrm{o}}$ 3, dezembro, 2010 
O esquema proposto por Backer apud Khisty e Lall (2003) relaciona as habilidades aprendidas, a motivação e as atitudes de condutores, caracterizando-as e identificando formas de intervenção ver Quadro 1.

\section{Quadro 1 - Características do Motorista}

\begin{tabular}{|c|c|c|c|}
\hline $\begin{array}{l}\text { Testes simples podem } \\
\text { deficiências. Relativa } \\
\text { através de educaçã } \\
\text { experiência unicamentt } \\
\text { de proficiência. }\end{array}$ & $\begin{array}{l}\text { emonstrar a maioria das } \\
\text { nente fácil melhorar } \\
\text { e treinamento. A } \\
\text { não é um bom indicador }\end{array}$ & $\begin{array}{l}\text { A maneira como o mo } \\
\text { muitas coisas frequentt } \\
\text { pouca segurança, muit } \\
\text { dirigir bem. Esses fator }\end{array}$ & $\begin{array}{l}\text { rista pensa e sente sobre } \\
\text { ente o leva a dirigir com } \\
\text { embora ele saiba e possa } \\
\text { são difíceis de analisar. }\end{array}$ \\
\hline $\begin{array}{c}\text { Conhecimento ou } \\
\text { informação }\end{array}$ & Habilidade e Hábito & Atitudes & Motivação \\
\hline $\begin{array}{l}\text { Ganhos através de } \\
\text { leitura, instrução e } \\
\text { observação. Testa-se } \\
\text { com breves exames. }\end{array}$ & $\begin{array}{l}\text { Ganhos pela prática. } \\
\text { Uma vez fixos os hábitos } \\
\text { não são facilmente } \\
\text { mudados. Testes } \\
\text { mostram necessidade de } \\
\text { treinamento. }\end{array}$ & $\begin{array}{l}\text { Frequentemente } \\
\text { determina como o } \\
\text { motorista reage a uma } \\
\text { situação (como pensa e } \\
\text { sente sobre a situação). } \\
\text { Atitudes podem gerar } \\
\text { comportamentos como: }\end{array}$ & $\begin{array}{l}\text { A importância atribuída } \\
\text { ao ato de dirigir com } \\
\text { cuidado é o que faz } \\
\text { tentar dirigir da melhor } \\
\text { maneira possível. A } \\
\text { motivação pode ser } \\
\text { associada a muitos } \\
\text { sentimentos diferentes, } \\
\text { tais como: }\end{array}$ \\
\hline $\begin{array}{l}\text { De Rodovias: } \\
\text { Superfície, } \\
\text { alinhamento, } \\
\text { sinalização horizontal e } \\
\text { vertical, etc. } \\
\text { De Veículos: Cuidado e } \\
\text { comportamento. } \\
\text { De Compartilhamento } \\
\text { de via. Regras viárias, } \\
\text { dispositivos de controle } \\
\text { de distância, } \\
\text { ultrapassagem, } \\
\text { comportamento de } \\
\text { outros usuários. }\end{array}$ & $\begin{array}{l}\text { Para fazer o veículo } \\
\text { obedecer; } \\
\text { Para reconhecer as } \\
\text { condições da via; } \\
\text { Para compartilhar a via } \\
\text { (prevendo falta de } \\
\text { educação de outros } \\
\text { motoristas); } \\
\text { Para resistir às distrações } \\
\text { e manter a atenção. }\end{array}$ & $\begin{array}{l}\text { Pressa desnecessária; } \\
\text { Comportamento } \\
\text { irresponsável; } \\
\text { Induzir corrida de carro; } \\
\text { Imprudência; } \\
\text { Chamar a atenção de } \\
\text { outrem. }\end{array}$ & $\begin{array}{l}\text { Medo de acidentar-se } \\
\text { Orgulho da própria } \\
\text { performance ao dirigir; } \\
\text { Responsabilidade social; } \\
\text { Desejo de servir como } \\
\text { exemplo; } \\
\text { Medo de crítica; } \\
\text { Medo de punição } \\
\text { (principalmente, prisão). }\end{array}$ \\
\hline
\end{tabular}

Fonte: Baseado em Backer, apud Khisty e Lall, 2003.

A problemática relacionada ao trânsito está envolta em uma série de eventos. Os acidentes podem ser considerados o resultado final de um processo que pressupõe um conjunto de fatores causais, sendo considerado o fator humano o principal responsável (Rozestraten, 1988). Assim, por qualquer ângulo que se observe a questão, o motorista frequentemente se encontra envolvido na causa dos acidentes.

\subsection{O comportamento de risco no trânsito: erros, lapsos e infrações}

Busca-se compreender por que condutores comportam-se no trânsito de forma arriscada, aumentando a probabilidade de sofrerem um acidente. Em virtude do crescente interesse pelo assunto, proliferam estudos teóricos e empíricos versando sobre o que leva os 
indivíduos a cometer determinadas infrações, que fatores afetam a condução e o comportamento de risco no trânsito (BENNER et al., 2007; WILDE, 2005; PARKER et al., 1995; REASON et al., 1990).

Existem pontos semelhantes em estudos realizados por diferentes autores que se debruçaram sobre o tema: a relação entre cometimento de erros, lapsos e violações e o risco de um possível envolvimento em acidentes (Reason et al., 1990; Parker et al, 1998 e Lawton, et al, 1997). Conforme Parker et al. (1995), a disposição para acidentes pode ser prognosticada a partir das infrações mencionadas pelo próprio condutor: informações as quais, em seu estudo, foram obtidas por meio da aplicação do instrumento Driver Behavior Questionnaire (DBQ) ou Questionário do Comportamento do Motorista (QCM), um instrumento de medida desenvolvido pelo grupo de pesquisa do comportamento de motorista - do departamento de psicologia da University of Manchester, que aborda estes comportamentos de riscos. É a partir dessa concepção que o conceito adotado para o comportamento de risco de condutores, neste projeto, será considerado pelo cometimento de erros, lapsos e violações, três tipos de comportamentos humanos no trânsito, conceituados e exemplificados no Quadro 2.

Quadro 2 - Definição de Lapsos, Erros e violações.

\begin{tabular}{|c|c|c|}
\hline Lapsos & Erros & Violações \\
\hline $\begin{array}{c}\text { Comportamentos } \\
\text { potencialmente embaraçosos, } \\
\text { envolvendo problemas de } \\
\text { atenção e memória. } \\
\begin{array}{c}\text { Comumente relatados por } \\
\text { mulheres e idosos. }\end{array}\end{array}$ & $\begin{array}{c}\text { Falhas de ações planejadas em } \\
\text { busca de resultados intencionais, } \\
\text { incluindo falhas de observação e } \\
\text { de julgamento de ações. }\end{array}$ & $\begin{array}{c}\text { Os comportamentos infratores, são } \\
\text { desvios deliberados, daquelas } \\
\text { práticas tidas como necessárias para } \\
\text { manter uma operação segura } \\
\text { (previstas - CTB). }\end{array}$ \\
\hline $\begin{array}{c}\text { Ex.: Esquecer onde deixou seu } \\
\text { carro no estacionamento. }\end{array}$ & $\begin{array}{c}\text { Ex: Não notar o sinal de "PARE" } \\
\text { e quase colidir com o fluxo de } \\
\text { tráfego com direito de passagem. }\end{array}$ & $\begin{array}{c}\text { Ex: Ignorar o limite de velocidade } \\
\text { de uma avenida. }\end{array}$ \\
\hline
\end{tabular}

Fonte: Lawton, et al., 1997, p. 1316; Parker et al., 1998.

Os erros apresentam-se como atitudes mais simples de serem minimizadas, por meio de treinamentos, reciclagens ou o desenvolvimento de formas de comunicação e informação aos condutores. Os erros se encontram nas habilidades aprendidas de conhecimento e informação, bem como nas habilidades e hábitos, como: controle de distância, ultrapassagem, reconhecimento das condições da via (buracos, congestionamentos).

As violações, porém, seriam mais complexas. As intervenções devem se dar por meio de uma mudança de atitude ou de estilo de vida que priorizem a segurança. Se enquadraria nos fatores motivação e nas atitudes dos motoristas consideradas difíceis de serem analisadas, como o comportamento irresponsável que induz à corrida de carro, o orgulho da própria performance ao dirigir e o medo da punição.

Dentro da perspectiva da avaliação dos comportamentos no trânsito e correlacionando com os resultados obtidos em outros países, Bener et al. (2007) realizaram 
um estudo intercultural comparativo sobre a média de violações, erros e lapsos do QCM. Entre os achados de sua amostra está a comparação com a realizada nos Emirados Árabes Unidos (EAU). Entre os países desenvolvidos com pesquisas semelhantes estão a GrãBretanha, a Finlândia, a Holanda e a Austrália. Constatou-se que os EAU apresentam um escore significativamente maior de lapsos, erros e violações, quando comparado à Austrália e a outros países europeus. Os homens tiveram um risco significativamente maior de acidentes em comparação com as mulheres dos Emirados Árabes Unidos.

\subsection{A Teoria da Homeostase do Risco}

Wilde pesquisador na área da psicologia do comportamento de risco constrói a Teoria da Homeostase do Risco (THR), nível aceito de risco presente no comportamento humano (saúde e segurança, em troca de benefícios esperados, como beber, divertir-se). Os indivíduos estabelecem seus próprios níveis de aceitação de risco ao realizarem uma atividade, muitas vezes assumindo riscos sem terem claras as consequências (WILDE, 2005).

O risco aceito não é necessariamente consciente, como o aumentar a velocidade para chegar mais cedo ao destino. Nesse exemplo, possivelmente não foi considerado o provável prejuízo, em função do aumento da velocidade: ser multado ou sofrer um acidente. O nível aceito de risco seria uma espécie de meta determinada por quatro fatores de motivação humana, os quais, aplicados ao trânsito, são demonstrados no Quadro 3.

Quadro 3. Nível aceito de risco: fatores de motivação humana.

\begin{tabular}{|c|c|c|c|}
\hline $\begin{array}{c}\text { Vantagens } \\
\text { arriscadas }\end{array}$ & $\begin{array}{c}\text { Custos esperados de } \\
\text { alternativas } \\
\text { comparativamente } \\
\text { arriscadas }\end{array}$ & $\begin{array}{c}\text { Benefícios esperados de } \\
\text { alternativas } \\
\text { comportamentais } \\
\text { comparativamente seguras }\end{array}$ & $\begin{array}{c}\text { Os custos esperados de } \\
\text { alternativas } \\
\text { comparativamente } \\
\text { seguras }\end{array}$ \\
\hline $\begin{array}{c}\text { Ganhar tempo } \\
\text { fazendo manobras } \\
\text { arriscadas ou indo } \\
\text { mais rápido }\end{array}$ & $\begin{array}{c}\text { Despesas de seguro } \\
\text { por estar errado num } \\
\text { acidente e multas. }\end{array}$ & $\begin{array}{c}\text { Desconto de seguro por } \\
\text { dirigir sem acidentes. }\end{array}$ & $\begin{array}{c}\text { Usar cinto de segurança } \\
\text { não confortável }\end{array}$ \\
\hline
\end{tabular}

Fonte: Wilde, 2005.

O comportamento de risco, muitas vezes, estaria então relacionado a motivações e conhecer e relembrar as vantagens e custos seria importante aos condutores. Segundo Hoffmann e González (2003), os condutores considerarem suas chances de sofrer um acidente menor do que a de outros. "As estimativas objetivas de risco tenderão a ser consideradas como algo significativo pela maioria dos condutores, somente quando avaliarem seu próprio comportamento" (p.378). Em muitos casos, a avaliação do próprio comportamento no trânsito só ocorre quando o motorista se salva de um possível acidente ou sofre realmente um.

\section{Legislação e fiscalização}

O Código de Trânsito Brasileiro CTB (Lei 9.503/97) institui também o sistema de pontuação, ou seja, além do pagamento da multa, o infrator terá contabilizados pontos 
referentes à infração, com os quais, ao totalizarem 20 pontos no prazo de um ano, o condutor terá sua carteira de habilitação suspensa.

Em relação às infrações, segundo o $\mathrm{CTB}$, estas são divididas em quatro grupos, conforme sua gravidade apresentados no Quadro 4.

Quadro 4. Valor das multas por grupo de infração e pontuação

\begin{tabular}{|l|c|c|c|}
\hline GRUPOS & TIPO DE INFRAÇÃ̃O & VALOR & PONTUAÇÃO \\
\hline Grupo 1 & Infração de natureza gravíssima & R\$ 191,54 & 7 pontos \\
\hline Grupo 2 & Infração de natureza grave & R\$ 127,69 & 5 pontos \\
\hline Grupo 3 & Infração de natureza media & $\mathrm{R} \$ 85,13$ & 4 pontos \\
\hline Grupo 4 & Infração de natureza leve & $\mathrm{R} \$ 53,20$ & 3 pontos
\end{tabular}

Como forma de classificação e ponderação dos pesos imputados aos erros, lapsos e violações, esses serão relacionados aos tipos de comportamentos previstos nas infrações. A relação estipulada pode caracterizar-se, de forma respectiva entre comportamento de risco e infração ou por semelhança atribuída. A classificação e o peso atribuído aos comportamentos de risco nas situações de trânsito, apresentadas no jogo TransRisco podem ser compreendidos com no exemplo.

Exemplo:

\begin{tabular}{l|l|l|}
\hline $\begin{array}{l}\text { Art. 208.(CTB) Avançar o sinal } \\
\text { vermelho do semáforo ou o de } \\
\text { parada obrigatória. }\end{array}$ & $\begin{array}{l}\text { Grupo: Infração } \\
\text { Gravíssima }\end{array}$ & $\begin{array}{l}\text { Violação - Atravessar um cruzamento } \\
\text { mesmo sabendo que o sinal já ficou } \\
\text { vermelho; } \\
\text { Multa: } \mathbf{R} \$ 191,54 .\end{array}$ \\
\hline
\end{tabular}

\section{A Aplicabilidade dos Jogos}

Conduzir um veículo pode ser considerado uma atividade complexa, na qual muitas variáveis estão interagindo, próprias do condutor, como do meio. Deste modo, os ambientes virtuais favorecem a construção de cenários que possibilitam a simulação de inúmeras situações, que permitam a interação do jogador com o ambiente simulado.

A utilização das Tecnologias de Informação no desenvolvimento de jogos pode favorecer o despertar de emoções, atitudes, e habilidades em seus jogadores. Segundo Ribeiro (2006), o desenvolvimento de um cenário virtual, através do jogo traz benefícios como: recria cenários de difícil acesso, temporários e perigosos; possibilita criar um espaço virtual localizado e uma diversidade de situações problemas e a construção de situações contextualizadas. Para a aprendizagem no trânsito, a possibilidade de criar ambientes com diversidade de estímulos, cenas típicas, situações problema, como um possível acidente, por descuido ao dirigir, em um ambiente controlado, são de grande valor.

Segundo Backlund et al. (2008), os jogos não são realistas, no sentido integral da condução, mas parecem ter um impacto sobre alguns aspectos da condução de um 


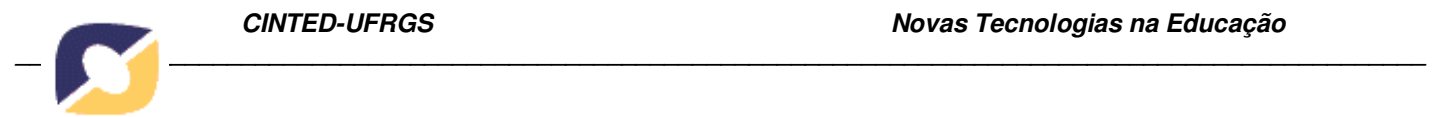

automóvel. O estudo da utilização desses recursos em jogos e simuladores de condução, portanto, vem auxiliar no desenvolvimento de uma metodologia de avaliação de motoristas, como no jogo digital com situações de trânsito.

\section{O Jogo TransRisco.}

Por ser um jogo com fins de avaliação, o TransRisco tem como propósito monitorar uma série de comportamentos durante o percurso do jogo frente a várias situações apresentadas. Do ponto de vista educacional, o desempenho no jogo, visa possibilitar o conhecimento do cometimento de comportamentos de risco a que o condutor se encontra suscetível, as implicações e conseqüências possíveis, como na apresentação da pontuação e valores gastos com as infrações cometidas, caso fossem cometidas realmente no trânsito.

O tema central proposto no Jogo são os riscos presentes no trânsito, pensando nisso, o jogo foi desenvolvido para acompanhar a performance do jogador/condutor ao conduzir um veículo em uma simulação, do espaço virtual de trânsito, que permita vivenciar e demonstrar suas atitudes ao dirigir. O cenário, assim, caracteriza-se por um ambiente de trânsito, na área urbana de uma cidade apresentando: quarteirões, casas, ruas, prédios, semáforos, veículos, pedestres, sinalizações de trânsito, com diversidade de sons e imagens. O jogador deve percorrer, para realizar a tarefa, um percurso no qual será submetido a 20 situações específicas de trânsito, com alterações no fluxo do trânsito, de pedestres, obstáculos na pista e a verificação de velocidade, por meio de controladores de velocidade.

Cada situação apresentada no jogo foi baseada em dados apresentados no QCM quanto a erros, lapsos e violações e infrações mais cometidas. As situações consideram, também, aspectos da teoria da Homeostase do Risco, que podem ser estressoras, desafiando o condutor como, por exemplo: a situação de congestionamento e pista livre, logo em seguida. Neste tipo de situação, verifica-se segundo Wilde (1995) que alguns motoristas, devido à pressa ou querer ganhar tempo, cometem a infrações de excesso de velocidade.

As infrações foram classificadas, segundo o CTB, em artigo, grupo, pontuação e valor da multa, conforme exposto anteriormente. Assim, além de verificar a freqüência do comportamento de risco este é avaliado quanto a sua gravidade, ao serem estipuladas pontuações variadas para as atitudes no trânsito, correspondentes a classificação de gravidade estabelecida no CTB. Todas as situações apresentadas durante o jogo são avaliadas. A Figura 1 apresenta uma situação de estacionamento. 

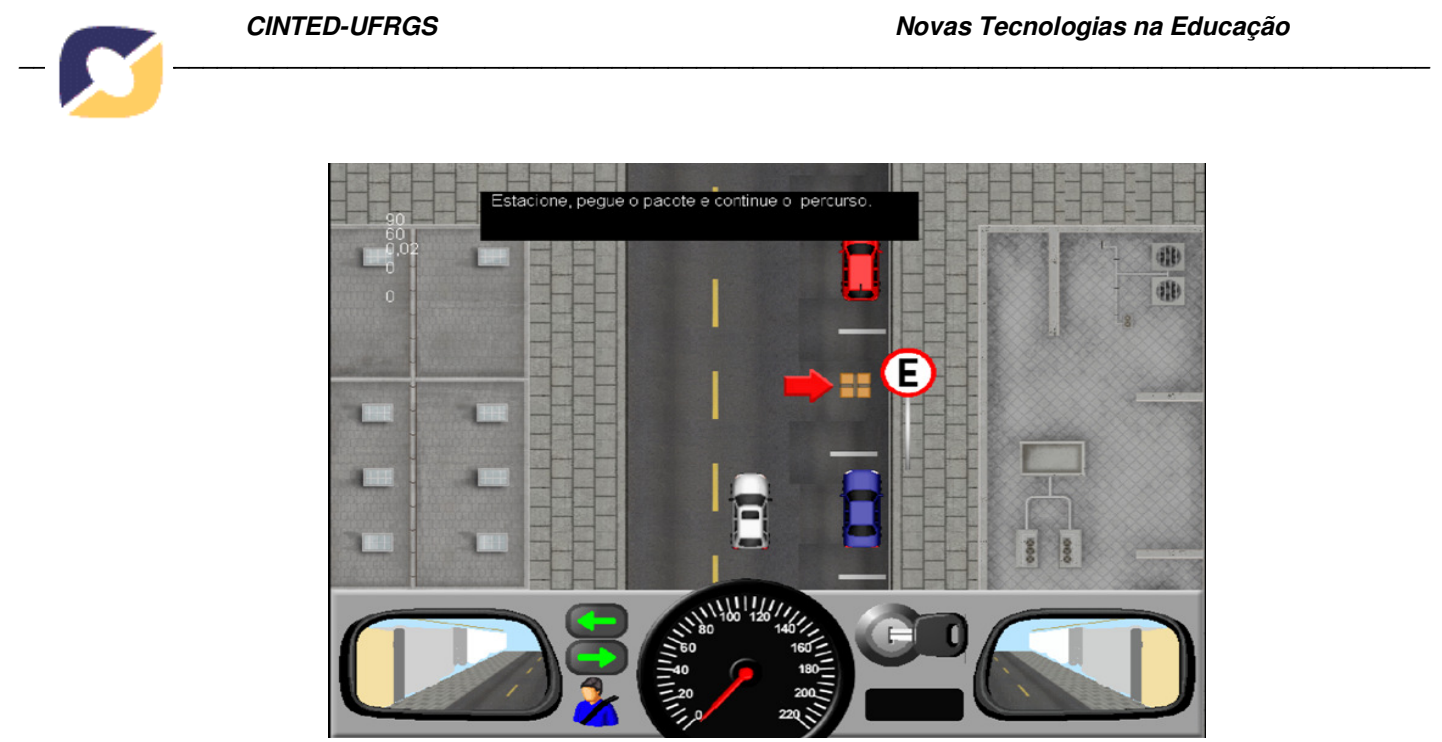

Figura 1. Imagem do TransRisco - estacionar.

Na situação de estacionar são avaliados os itens demonstrados no Quadro 5.

\section{Quadro 5. Classificação}

\begin{tabular}{|l|c|c|c|}
\hline Situação & Pontuação & Valor/Multa & \multicolumn{1}{|c|}{ Comportamentos de risco } \\
\hline $\begin{array}{l}\text { Cena - } \\
\text { Estacionar }\end{array}$ & 5 pontos & R\$127,69 & $\begin{array}{l}\text { Violação - Não Sinalizar com Antecedência.ao } \\
\text { estacionar para pegar pacote. } \\
\text { Violação - Não Sinalizar com Antecedência. saída } \\
\text { da vaga, que se encontra estacionado. } \\
\text { Erro - Deixar de checar o espelho retrovisor antes } \\
\text { de sair da vaga que se encontra estacionado. }\end{array}$ \\
\hline
\end{tabular}

O jogo TransRisco estrutura-se em situações de trânsito, em que o condutor deve demonstrar seu desempenho, o qual pode apresentar um comportamento correto, não pontuado, ou erros, lapsos e violações os quais serão pontuados, conforme exemplo do Quadro 5. Ao final do Jogo será proporcionado ao jogador o total de sua pontuação, que pode chegar a 100 pontos, quanto mais pontos, mais elevado é o grau de risco de seu comportamento, que será classificado quanto ao Grau de incidência de risco que pode ser: Sem, Leve, Médio, Grave ou Gravíssimo.

Para a concretização das idéias propostas, nesta versão do jogo digital TransRisco, contou-se com a colaboração da empresa Hope Revolution Programas e Jogos Didáticos Ltda. O jogo foi desenvolvido em Game Maker com a extensão Resource System, o desenvolvimento gráfico em Blender 3D e Gimp e para os efeitos sonoros utilizou-se Audacity. O Jogo é compatível com máquinas IBM/ PC, sistema operacional Windows/XP/ Vista/7. O Tamanho do Jogo é de 37,97 MB. Como periféricos utilizou-se um Volante com botões e pedais para PC's (Figura 2). 

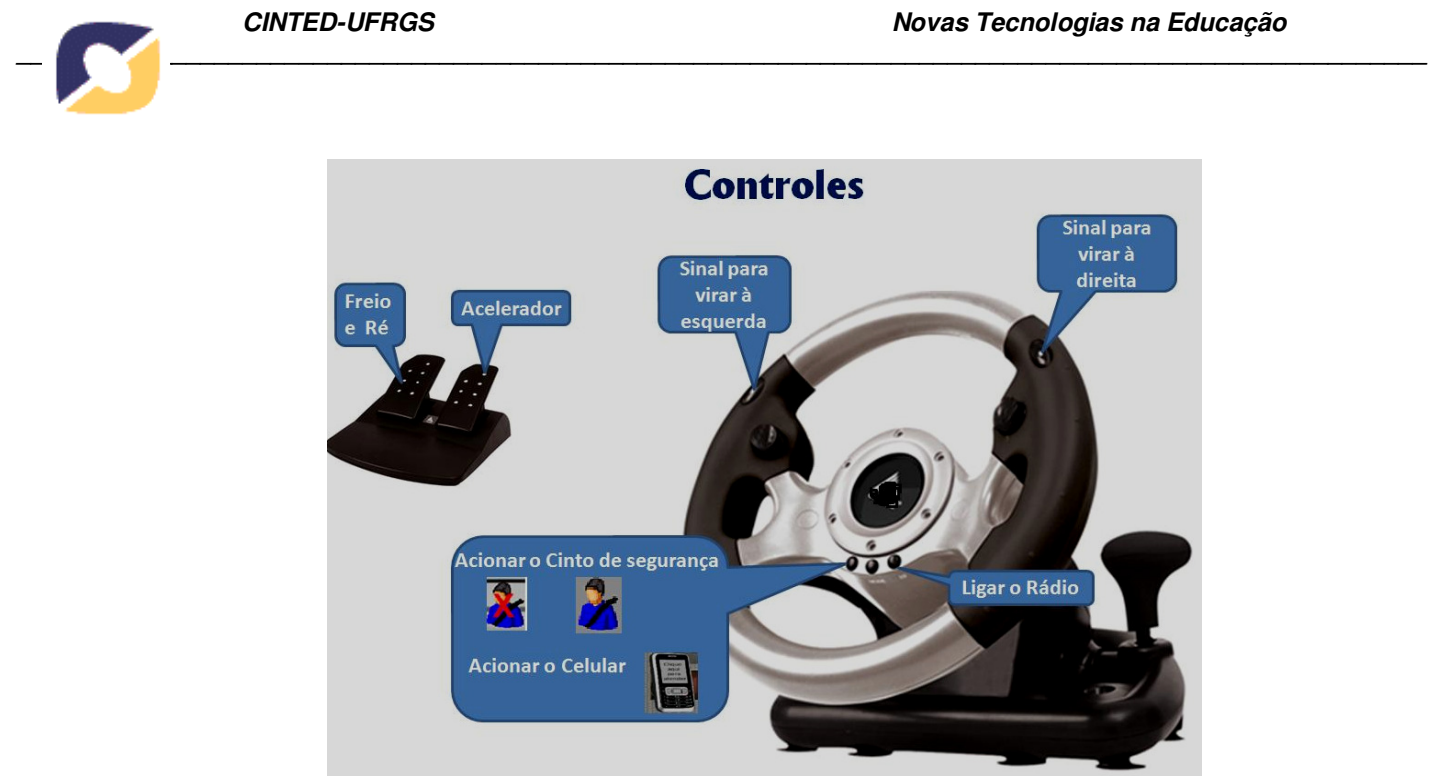

Figura 2. Comandos no Volante e pedais

A partir desse instrumento, pretende-se examinar o comportamento do condutor ao dirigir e a partir dos dados levantado, fornecer ao jogador um feedback sobre seu desempenho no jogo quanto à incidência de comportamento de risco durante o percurso e às respectivas sanções, como pontuação e valores gastos com as infrações cometidas, caso estas fossem perpetradas realmente no trânsito, conforme o CTB.

\section{Conclusões}

As questões sobre trânsito e principalmente os elevados índices de acidentes merecem atenção e estudos científicos. A chave de um progresso educacional significativo pode estar na apreciação das deficiências dos motoristas e no desenvolvimento de condutores mais conscientes de sua conduta e informados.

Comportamentos arraigados de desrespeito às normas de trânsito são complexos e exigem estratégias como fiscalizações constantes, punições e ações educativas. Desta forma, possibilitar por meio de jogos que o motorista se confronte com seu comportamento, pode ser uma estratégia significativa. Em alguns casos, propiciar um feed-back ao usuário a respeito de seu desempenho pode servir para a tomada de consciência de seu comportamento ao dirigir.

A segurança no trânsito partiria desta conscientização e de treinamento de ações corretas no trânsito. Os estudos com jogos e simuladores, nesta área, permitem observar, em meio a um ambiente controlado, variáveis que interferem no desempenho dos condutores e a partir disso formular ações preventivas.

Os jogos eletrônicos e os programas de realidade virtual podem servir de espaços para a significação e a resignificação, ao permitirem trabalhar questões de conhecimento, atitudes, antecipações, levantando hipóteses. Em vista disso, acredita-se que a metodologia de identificação e avaliação dos comportamentos de risco proposta e a apresentação aos 


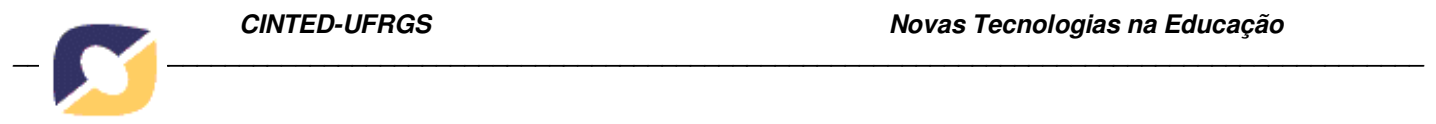

condutores do grau de incidência de riscos a que se submetem ao dirigir possam auxiliar na prevenção de situações de risco no trânsito.

Esperando-se que o instrumento de avaliação, proposto, venha a contribuir na intervenção em Centro de formação de condutores (CFCs), treinamentos corporativos, cursos, pesquisas e em outras aplicabilidades, além de colaborar para o desenvolvimento de trabalhos de fiscalização e educação para o trânsito.

Os resultados coletados, inicialmente, nas aplicações do jogo em condutores de CFCs, de Porto Alegre, já estão demonstram que as infrações relatadas pela EPTC como mais freqüentes, correspondem com os primeiros dados adquiridos sobre o comportamento de condutores no Jogo. Destacando-se, o excesso de velocidade e o uso de celular como os comportamentos de risco mais apresentados pelos jogadores.

\section{Agradecimentos}

Ao apoio do $\mathrm{CNPq}$

\section{References}

Brasil (2007). "Código de Trânsito Brasileiro". Disponível em: www.senado.gov.br/web/codigos/transito/httoc.htm. (Acesso em: 20 abril 2009).

Backlund, Per; Engström, Henrik \& outros (2008). "Games for traffic education: An experimental study of a game-based driving simulator". Simulation \& Gaming, May, 19.

Bener, A., D. Crundall., et al (2007). Driving behaviour, lapses, errors and violations on the road: United Arab Emirates study." Advances in Transportation Studies an international Journal", 12.

Diogenes, Mara Chagas. (2004) "Indicadores de Desempenho no Gerenciamento da Segurança Viária". Dissertação Mestrado Acadêmico. Engenharia de Produção UFRGS. Área de Transportes.

Hoffmann, M. H; González, L. (2003) "Acidentes de trânsito e fator humano". In: Hoffmann, M.H (org). Comportamento humano no trânsito. São Paulo: Casa do psicólogo, 2003. p. 377-391.

KhistY, C. Jotin; Lall, Kent. (2003). "Transportation Engineering: An Introduction".

Konstantopoulos, P; Crundall, D.(2008). The Driver Prioritisation Questionnaire: Exploring drivers' self-report visual priorities in a range of driving scenarios. "Accident Analysis and Prevention", v 40, p. 1925-1936.

Lawton, Rebeca; Parker, Dianne; Manstead. (1997) “ The Role of Affetc in Predicting Social Behaviours: The Case of Road Traffic Violations", Journal of Applied Social Psychology, v. 27, n 14 , p. 1258-1276.

Parker, Dianne; Lajnen, Timo; Stradling, Stephen. (1998) "Attitudinal Predictors of interpersonally aggressive violations on the road". Transportation Research Part F: Traffic and Transport Psychology, v. 1, p. 1-14.

Parker, D; Reason, J.T; Manstead, A. S \& Stradling, S.G. (1995) "Driving errors, driving violations and accident involvement". Ergonomic, 38:5, p. 1036-1048.

Pirito, Ma. (1999) “Considerações sobre o Motorista Idoso”. São Paulo: ABRAMET p. 25-

V. $8 \mathrm{~N}^{\mathrm{o}}$ 3, dezembro, 2010 
27.

Reason, J. T.; Manstead, A. S. R.; Stradling, S.; Baxter, J.; \& Campbell, K. (1990) "Errors and violations on the roads: a real distinction". Ergonomics, v. 33, p. 1315-1332.

Ribeiro, Luis Otoni Meireles. Timm, Maria Isabel e Zaro Milton Antonio. (2006) "Modificações em jogos digitais e seu uso potencial como tecnologia educacional para o ensino de engenharia". RENOTE - Revista Novas Tecnologias na Educação, CINTED-UFRGS. $\quad$ v. $4 \mathrm{n}^{\circ} 1$, Julho. Disponível em: www.cinted.ufrgs.br/renote/jul2006/artigosrenote/a36_21203.pdf

Rozestraten. R. J. "Psicologia do Trânsito, conceitos e processos básicos". (1988). S.Paulo: EPU/EDUSP.

Wilde, G. (2005) "O limite aceitável de risco: uma proposta sobre segurança e saúde”. São Paulo: Casa do Psicólogo. 